\title{
CONCENTRATION AS A GEOLOGICAL PRINCIPLE
}

\author{
PRESIDENTIAL ADDRESS BY ISRAEL C. RUSSELL * \\ (Read before the Society December 27, 1906)

\section{CONTENTS}

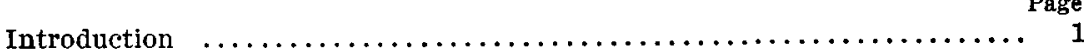

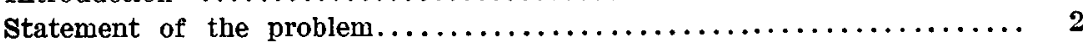

Analysis of the processes of geological concentration............... 3

Primary dirisions........................................ 4

Mechanical concentration............................... 6

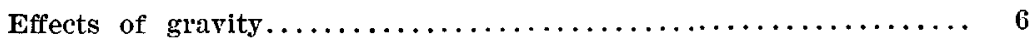

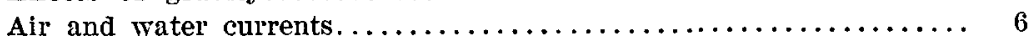

Ice currents.................................... 8

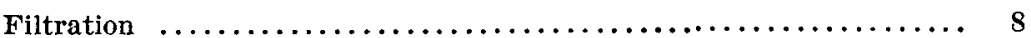

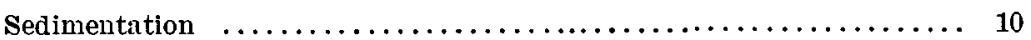

Mechanical concentration of liquids and gases................. 11

Selective power of gravitation....................... 11

Splere of influence............................... 12

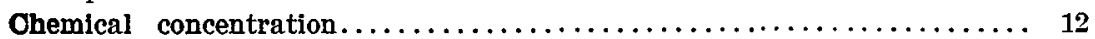

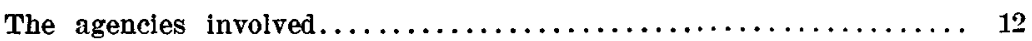

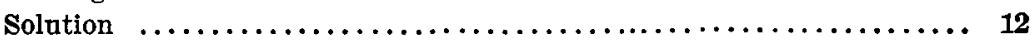

Residual concentrates............................ 13

Surface and subsurface precipitates.......................

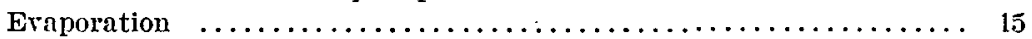

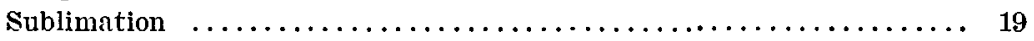

Chemical reaction resulting in precipitation.................. 20

Phrsical-chemical concentration.......................... 22

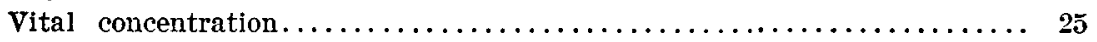

The agencies involved......................................

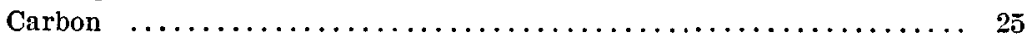

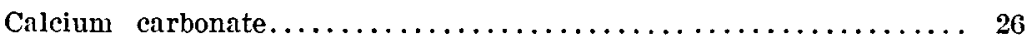

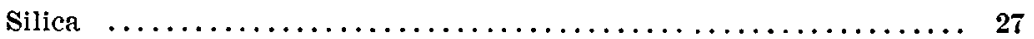

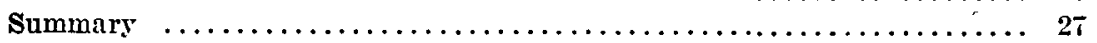

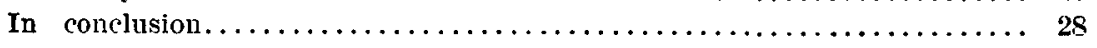

\section{INTRODCCTION}

It is a matter of current knowledge among geologists that rarious mineral substances of a greater or less degree of purity are at the present

* Owing to the death of President Russell, this paper was read by Acting President Daris.

Manuscript receired by the Secretary of the Society December 28. 1906.

I-Blel. Geor. SoC. AM., Vor. 18, 1906 
time being separated through the agency of natural processes from other substances or gathered from a previously widely disseminated state and placed by themselves. To this general process the term geological concentration has been applied. It is also well known from the study of mineral veins, residual earths, etcetera, that similar processes of concentration have been in operation throughout geological time, and that in obedience to a law of nature, as yet inscutible, whereby like seeks like, most mineral substances of commercial value have been segregated in veins, beds, and other deposits, and thus become available for human uses. No systematic attempt seems to have been made, however, to formulate the many and frequently highly complex processes by which the concentration of mineral substances through the action of natural agencies is brought about. It is with this phase of geological study that the present address is concerned.

\section{Statement of the Problem}

During the flow of streams heavier is separated from lighter material in suspension or rolled along the bottom, and gold, platinum, tin ore, and other substances of high specific gravity are frequently retained in depressions of the stream's beds, while substances of less specific gravity are carried on. Water emerging at the earth's surface as springs contains calcium carbonate, silica, etcetera, in solution, which in many instances are deposited as chemical precipitates. Plants select carbon from the carbon dioxide of the air and secrete it in their tissues, thus accumulating material suitable for the production of beds of peat and coal. These and other similar or analogous processes whereby concentration of mineral matter results are now in operation and should, as it seems, to be duly recognized as constituting a distinct and important chapter in dynamical geology.

Under the uniformitarian doctrine that "the present is the key to the past," it is evident that a study of the processes by which the concentration of mineral matter is now being brought about should furnish a means for determining the nature and mode of action of the processes by which similar results were produced during past time. In other words, a knowledge of the processes of concentration now in operation furnishes a means for translating the records of former combinations of agencies and conditions into terms which may be defined by observing the results produced by similar combinations at the present day. In the same manner that ripple-marks, shrinkage cracks, raindrop impressions, etcetera, on ancient sandstones furnish evidence as to the geographical 
and physical conditions which prevailed during former stages in the earth's history; and in the same manner, also, that fossils enable one to trace the evolution of species, genera, etcetera, of animals and plants or to follow the migrations of floras and faunas during former geological periods, so a knowledge of present processes of concentration shed light on many pages of geological history which otherwise would remain in shadow. Not only do the principles governing the concentration of mineral matter furnish a tool for use in general geological investigations, but one which is of practical utility to the economic geologist and mining engineer. For example, it is only when the processes of concentration which have led to the formation of a bed of coal or that filled a fissure with ore are understood that predictions worthy the name can be made as to the extent of such deposits or reliable advice given in reference to the localities and associations most suggestive of their presence.

In a preceding paragraph examples of what is meant by the term concentration were cited. One of the processes, namely, the separation of gold, platinum, etcetera, from associated debris is obviously controlled by physical conditions; another, the precipitation of calcium carbonate and silica from the waters of springs, is dependent in part at least on chemical conditions; and still another, the secretion of carbon in the tissues of plants, necessitates the action of vital functions. These illustrations suggest a method for classifying the various processes by which mineral matter is concentrated, thus rendering it practicable to give concrete shape to the tool we wish to fashion. The suggestion is that the many and varied processes by which concentration is brought about may be arranged in orderly sequence with reference to the nature of the chief or controlling force by which the selection, transportation, and deposition of the material segregated is rendered possible.

\section{analysis of the Processes of Geological Concentration}

The activities which lead to the separation of one kind or of a definite combination of matter from other kinds or combinations of matter, the transfer of the selected material to a new locality, or more or less complete isolation of a residue, precipitate, etcetera, are: (1) physical force, (2) chemical force, (3) the intimate and interdependent combination of molecular and atomic activities termed physical-chemical force, and (4) the property inherent in living organisms which is designated as vital foree. Under the influence of one or another of these four divisions of energy as a dominant factor, it seems practicable to arrange all the processes of concentration now in operation or which can be shown to 
have been formerly active. With this idea in mind, the diverse and frequently highly complex processes of concentration may be conveniently classified as mechanical, chemical, physical-chemical, and vital processes.

To be sure, in attempting to classify the processes whereby concentration is effected, as in most other similar efforts to tabulate natural phenomena, the divisions which it is convenient to establish are largely empirical. The dividing lines are not in all cases definite and sharply defined, but resemble rather the recognition of species among organisms or the partitioning of prairie lands among various owners. In many and perhaps most instances, however, in which natural methods of concentration are in operation, some one physical, chemical, physical-chemical, or vital process is dominant and determines the major characteristics of the resultant product. In the recognition of the dominant factors opinions may differ, as they do concerning species among plants and animals, but this qualification need not detract from the utility of the general principle which it is the purpose of this address to emphasize.

\section{Primary Divisions}

It is obvious from current geological knowledge concerning the various processes of erosion, transportation, and deposition that an extensive group of concentrates have resulted mainly and essentially from the mechanical changes which take place on the earth's surface. A typical example is furnished by the way in which dry, heterogeneous debris is separated by the winnowing action of the wind into residual material, too heavy for the wind to move, and graded accumulations formed by the deposition of the transported material. In this process mechanical action, or force, is the dominant agency leading to the results referred to, and all similar processes may be conveniently grouped under the term mechanical concentration.

In a similar manner in many instances chemical changes are in control and lead to the isolation of residual material and the accumulation of graded precipitates or other deposits. In many of the operations of nature, however, which result in concentration the part played by the physical processes and by chemical processes are so equally balanced that no plane of cleavage between the two can be detected. In a manner analogous to the recognition of the science of physical chemistry to embrace the borderland between two long recognized sciences, it seems permissible to differentiate physical and chemical processes of concentration on the one hand from physical-chemical processes on the other. Assistance in this direction may be had by recognizing the dominant 
field of action of the three groups of processes under consideration. The field of action of the processes of concentration in which either physical agencies or chemical agencies are in a large majority of instances clearly dominant is the outer portion of the earth and includes the zone of contrast of the atmosphere with the lithosphere and the zone of weathering on the outer earth. The portion of the earth in which physical and chemical agencies favoring concentration go hand in hand and are to a conspicuous degree mutually interdependent has as its superior or outer limit the base of the zone of weathering and includes the zone of concentration and the eentrosphere, or the inner earth.

In reference to what is termed above the outer earth, temperature and pressure are low in intensity and have but small yearly fluctuations, but within this narrow boundaries are subject in each instance to rapid fluctuations both at a given locality and from place to place. In the inner earth both temperature and pressure are of a high order of intensity, in each instance increase with depth, and soon reach what may be termed incomprehensible values, but are without yearly variations and during even secular changes are modified but slowly.

In the first of the provinces thus defined, namely, the outer earth, the part played by dominantly chemical and dominantly physical processes of concentration may be differentiated and chemical concentrates given equal rank with the mechanical concentrates.

In the second province, namely, the inner earth, physical conditions, and principally temperature and pressure, are, as nearly as can be judged, equal and perhaps of greater importance than the conditions usually designated as chemical, which bring about concentration. The two, however, are so intimately associated and so thoroughly introactive that their combined influence only can be consistently used as a basis of classification in the present connection. Physical-chemical forces are therefore given equal rank with the dominantly mechanical and dominantly chemical forces which lead to concentration.

Again, under the influence of life, physical and chemical changes are guided by a force not recognizable in the inorganic world, and through its action matter is given an organic structure comparable in rank with the crystalline structure in the inorganic world. Through the dominant action of vital force certain substances are differentiated from other substances and concentrated to form the tissues of plants and animals. Still further concentration by the organic bodies themselves may result by the action of mechanical agencies or from chemical changes, but the accumulations of solid organic debris or of liquids or gases arising from the decomposition of such material when accumulated so as to form a 
geological deposit may justly be termed an organic concentrate. Vital force may thus be ranked with mechanical, chemical, and physicalchemical forces as a primary agency leading to the concentration of matter.

\section{Mechanical Concentration}

\section{DFFEOTS OF GRATITY}

Gravity acting singly, as when talus slopes are formed and avalanches occur, or with assistance of such a transporting agency as is furnished by glaciers, may lead to the concentration of heterogeneous accumulations. When, however, gravity works in conjunction with a transporting agency in a liquid or gaseous condition it is enabled to record a selective power holding certain objects in place while their associates are moved, and during the time the material moved is in transit causing certain portions to come to rest while others are carried on. The media with the aid of which gravitation is enabled to separate more or less perfectly the component parts of heterogeneous mixtures of mineral and rock fragments are principally air and water currents. It is in this connection that the best illustrations of the principles governing mechanical concentration occur.

\section{AIR AND WATER CURRHNTS}

With the aid of air currents, gravitation causes the separation of lighter from heavier material, of smaller from larger fragments, of rounded from angular grains, etcetera. The material which the wind is capable of removing is more or less completely carried away and a residuum usually remains. Two important phases of the general process of concentration are thus illustrated: first, the concentration of material that is left as residue, owing to the removal of certain varieties of material previously present, and, second, the accumulation of the material removed in more or less perfectly graded deposits.

Examples of mechanical concentration in which air currents are the controlling agency are furnished: first, by the stones, gravel, etcetera, on wind-denuded areas, as desert plains, and, second, accumulations of gravel, sand, and dust, which are formed where wind-transported debris comes to rest. This comprehensive and important process, which has been in operation since debris first became dry on the earth's surface and was moved by the wind, corresponds to the winnowing of chaff from grain. In seeking to supply a knowledge of the principles governing eolian concentration as an aid in discovering products of commercial importance, not only the piles of chaff composing dust, soils, sand dunes, 
etcetera, should be examined, but search made for the grain left on windswept areas, with the hope of discovering gems and flakes and nuggets of gold, platinum, and other heary metals and ores.

An important adjunct to the process of eolian concentration is furnished by explosive volcanic eruptions. During such eruptions the ratio of the size, weight, and shape of the fragments blown into the air to the propelling force leads to an assorting of the debris showered on the earth's surface, but assisting this process, and, as it seems, usually assuming the leading role, is the transporting power of air currents. During the operations of either the propelling or carrying agency, however, the selective power of gravity may be credited such assorting as takes place of the material discharged.

With the aid of water currents, gravitation leads to the selection from heterogeneous debris of certain classes of material for transportation and the leaving of other classes of material as residues. Concentration of material, owing to the removal of other kinds of material previously mingled with it, through the combined action of water currents and gravitation, is of the same nature as the similar process already noted in the case of air currents, but from a geological point of view is vastly more important. Examples of residual material concentrated through the agency under consideration are furnished by the boulders and stones in stream beds and on the beaches of the ocean and of lakes, in numerous now abandoned waterways and along ancient coast lines.

In the process of stream and current transportation, mineral and rock fragments carried in suspension or rolled and pushed along the bottom are assorted with reference to size, gravity, and shape and are finally deposited in more or less perfectly assorted accumulations. Witnesses to the importance of this process are furnished on every continent by extensive beds of assorted debris, like gravel, sand, clay, etcetera, and by thick and extensive strata composed of consolidated material of like character. A special phase of the process is illustrated by the manner in which grains and nuggets of gold, platinum, cerussite, etcetera, are concentrated in depressions and crevices in the beds of streams and the currentswept shores of standing water bodies. So well known is the process referred to that it is employed in many ways in the arts, as, for example, the separation of heavy minerals from crushed rock on the concentrating tables used in certain metallurgical operations.

A knowledge of the laws governing transportation by water currents and the secondary or associated conditions which modify their operation is of prime importance in searching for localities where fractional parts of former heterogeneous stream loads have been laid aside. The practical 
phases of this far-reaching principle have been worked out in detail by the placer miner.

Modifying the action of gravitation in its selective work when aided by air or water currents is at times the physical condition of the surface over which the currents carry debris. Degree of roughness is here an important and frequently a controlling factor, as is illustrated by the natural riffles which catch and retain grains of gold, but other conditions may favor the exercising of a selective preference. Variations in molecular attraction or adhesion and in chemical affinity between the various fragments transported, or between the material carried and the surface with which it comes in contact, are, as it seems, minor phases of what is in the main a mechanical process. The selective power manifested by mercury for gold in the troughs of the sluices used by placer miners and the peculiar selective property that grease has for the diamond, as illustrated on the concentrating tables used at the South African diamond fields, should lead geologists to look for analogous processes under natural conditions.

\section{ICE CURRENTS}

While air and water currents furnish the chief determining or qualifying conditions which cooperate with gravitation in bringing about the mechanical concentration of debris, at least analogous results are produced by ice currents. Glaciers, however, have but little, if any, selective or assorting power, but both the residue they leave-if such a term is permissible in reference to the debris they sometimes pass over without securing-and the deposits they make are characteristically heterogeneous. An assorting of the debris composing surface and marginal moraines does occur, however, owing to the rolling and sliding of the larger or more spherical stones present on steep slopes, and a rude sort of concentration is brought about during the accumulation of moraines; but these minor results of the work of sluggish and inflexible ice currents do not require consideration at this time.

\section{FILTRATION}

Associated with the transportation of debris in suspension by water currents is the process of natural filtration. Although this process has received but scant attention from geologists, its functions are evidently of vast importance. The direct influence of filtration in concentrating debris or in leading to the accumulation of material of economic importance is less obvious than the restraining influence it exerts on the 
action of agencies tending to remove and perhaps redistribute accumulations of debris brought about in various other ways.

The function of filtration is the separation of solid substances in suspension in liquid from the containing liquid. In all geological processes of this nature the containing liquid is water. Land areas on which rain falls may be considered as filters of vast extent. Rain drops on striking the ground in many instances disturb fine particles on which they impinge and take them into suspension. In fact, the accumulated rain drops gather into surface streams which bear away this freight of silt, but in part the water sinks into the ground and is filtered. When the filter is coarse no material of sufficient fineness to form soil remains, and barren areas of angular rocks, boulder pavements, form the surface. When the filter is of fine texture, however, and when plants assist in binding its particles together, efficient filtration results, as is abundantly proven not only by the conservation of the soil present, but by the clearness of the springs formed when the filtered water emerges once more at the earth's surface. It is to the conservative influence of filtration that the preservation and fertility of soils is largely due. By this same process, also, the beds of streams when of an open texture are rendered impervious. In such instances the meshes of the filter become clogged with the material separated from the water which percolates through them.

Downward percolation favors the solution of debris previously in suspension at the surface of the land. Lateral filtration, especially through mats such as are present in swamps, is also an important process leading to the concentration of silt and of the fractional solid products arising from the maceration of organic bodies.

While the direct influence of filtration in assisting in the concentration of mineral substances of commercial value awaits detailed investigation, the suggestion is pertinent that in certain instances the retention at a given locality of surface precipitates, as, for example, bog iron ore, may be due in a determinable measure to lateral filtration through vegetable mats. Possibly, also, when chemical precipitates are formed in fissures or other openings in rocks, filtration in certain instances may be a part of the process of which the solid particles produced are prevented from becoming widely disseminated.

In studying the influence of filtration, it needs to be remembered that there is but an indefinite boundary between well characterized examples of the process and the influence of obstruction on more or less completely debris-charged air and water currents. The rushes growing in a stream 
may cause sedimentation by checking the current or producing eddies, while a mat of sphagnum might lead to the complete classification of percolating water; but there is no definite boundary between the two agencies, so far as their physical action is concerned.

\section{SEDIMENTATION}

In the brief outline just given of the functions of air and water currents in promoting the concentration of either inorganic or organic debris, the selective process performed by gravity was made prominent. This same group of changes, visible in a different way, has in part been termed sedimentation. The operation of currents, however, is not strictly essential in the process of sedimentation, although under natural conditions almost always present, as an assorting of debris in suspension in still water, takes place. In still water, substances of less specific gravity than the water, whether fresh or saline, rise to the surface, thus indicating concentration, which, should currents be present, leads to still further concentration, as in the eddies of streams, in ocean currents, etcetera. Material of greater specific gravity than the water in which they are suspended descends under the pull of gravity and is assorted, in reference to the ratio of volume and weight. A like result follows when debris is suspended in still air and graded layers of dust and of dust-like particles result.

In the case of heterogeneous fragments in a minute state of subdivision, in suspension in water, other conditions, as the molecular attraction of particle by particle, the chemical nature of the substances in solution in the water, and their relative proportions, and yet other and still less well understood conditions, as, for example, in reference to electricity, become important functions. An illustration is furmished when streams deliver fine silt in suspension to the ocean and flocculation on account of the substances in solution in sea water occurs, which quickens the rate of sedimentation.

The importance to the geologist of the process of sedimentation in leading to the concentration of fractional parts of previously heterogeneous debris, whether inorganic or organic, is attested by the accumulations that are present on the floor of streams, lakes, and the ocean. The fact that like results have been attained throughout geological history is made evident by the extensive and frequently thick strata of shale, sandstone, limestone, etcetera, and by similar metamorphosed sediments in various geological terranes. 
The importance to industry of the results of the processes of concentration just considered is illustrated by the manifold uses of stratified deposits of gravel, sand, and clay, by a large class of building stone, metals obtained from placer mines, and by many other accumulations.

\section{MECHANICAL CONCENTRATION OF LIQUIDS AND GASES}

In the above outline review of the various processes by which mechanical agencies lead to the concentration of various classes of products, only matter in the condition of a solid has been considered. The far-reaching principle involved, however, applies to the gathering together under certain conditions of liquids and gases. The extent and importance of this phase of the subject is illustrated not only by lakes, seas, the ocean, ground water, which require only mention at this time, but by certain more special or more exceptional occurrences, such as the accumulation of petroleum and rock gas in porous terranes beneath impervious and at times arched roofs, and in fissures, caverns, and other openings. The process of concentrating gases heavier than air at the earth's surface is exemplified by the accumulation of carbon dioxide in Death gulch, in the Yellowstone National Park, and many other similar instances elsewhere.

In the case of liquids and gases concentrated in these several ways, either at the earth's surface or in the outer portion of the lithosphere, it is a prerequisite that receiving reservoirs should be present, but in searching for the dominant principle which leads to the transfer of liquids and gases from one locality to another and their accumulation, particularly in commercial quantities, it is evident that gravitation plays the leading part.

\section{SELEOTIVE POWER OF GRAVITATION}

In the various assorting processes controlled principally by gravity a selective power is exercised with reference to certain physical properties and the ignoring of other similar properties. For the most part, gravity takes note of the ratio of weight and volume, but in part makes a selection in reference to form, and again derives assistance from molecular attraction, and from electrical or other but little known or but imperfectly understood conditions.

In a negative way it may be said that mechanical processes of concentration take no account of chemical composition, crystalline or other structure, or of color, hardness, or elasticity, except so far as their properties affect size, weight, shape, or attraction or repulsion.

Mechanical concentration is in brief a physical process leading to the 


\section{I. C. RUSSELL-CONCENTRATION AS A GEOLOGICAL PRINCIPLE}

accumulation of solids, liquids, and gases with certain like physical properties.

\section{SPHERE OF INFLUENCE}

The field of operation, so to speak, of the various processes which bring about mechanical concentration is essentially the earth's surface. Included in it are the lower portion of the atmosphere, with an indefinitely defined outer limit, the waters of the earth's surface, or what may be termed the free hydrosphere, and the outer film of the lithosphere. To some small extent the processes in question perform their functions in caves and fissures, but below a depth of a few score meters from the surface of the lithosphere the conditions on which their activities depend cease to exist. Former land surfaces and ancient lake and ocean beds, however, are now in many instances buried beneath subsequently formed aqueous or igneous terranes, and ancient mechanical concentrates are present far below the present surface of the earth.

\section{Chemical Concentration}

\section{THE AGENCIES INVOLVED}

The processes of concentration which are characteristically of a chemical nature result principally from solution and precipitation, but others, which are dominantly chemical changes, such as sublimation, crystallization, replacement, etcetera, play important roles.

\section{SOLUTION}

Concentration by solution results in two classes of products: First, residue or the fractional parts of substances acted on by solvents which remain when their more soluble associates are removed in solution, and, second, the material entering into solution which may or may not be more highly concentrated than during its previous state, but which in many and probably most instances is in a condition favoring later concentration, owing to precipitation or some other process.

The process of concentration by solution under natural conditions includes solvent action of gases, liquids, and solids; but for the present only the part taken by liquids, and still more strictly, only the action of water, will be considered. No change known to have occurred in the material composing the earth is, perhaps, more important or carries with it such far-reaching geological results as the familiar process of solution. The underlying principle is that a selective action is brought into play, since the solubility of varions substances, as it seems, has as wide a range 
as do the combined physical and chemical properties of all the substances entering into the composition of the earth.

\section{RESIDUAL CONCENTRATES}

Owing to the selective power of water, the universal solvent, certain substances under prescribed conditions, especially of temperature and pressure, are taken into solution and carried away, leaving in many instances other substances as a residue. The world-wide importance of this process is forcibly shown by the abundance throughout many extensive regions of residual earth. The familiar terra rossa, consisting essentially of iron-stained clay, no matter what may have been the nature of the rock from which it was derived, is evidence that the process of selective solution carried on by percolating water aided by organic acids is a most important agency leading to the disintegration of the rocks forming the superficial film of the lithosphere and the concentration of a part of the resultant debris.

The principle illustrated by the mode of origin of terra rossa applies to many other substances, some of them of great industrial value. Among the numerous examples that might be selected, none, perhaps, will serve better than the so-called fossil iron ore of the Clinton formation in the Appalachian region, which in certain important instances, if not in all cases, has resulted from the leaching of ferruginous limesione; the more soluble constituents of the rock having been removed in solution, leaving the less soluble ferric oxide as a residual concentrate. Again, in the lead and zine mining districts of the Mississippi valley and the silver and gold fields of the Pacific mountains and elsewhere, natural concentration produced by the removal of the more soluble constituents from mineralized rocks, mineral veins, etcetera, has led to the concentrating of residual minerals and ores of great commercial value.

Knowing the process by which residual concentrates are produced and the nature of the material from which they are derived, guides are furnished which aid in the search for rock residuums. Important principles in this connection are: The process goes on most actively where rain is abundant, the temperature high, and plant life luxuriant. Each of these dominant conditions, as a further analysis would reveal, is dependent on other conditions, which we denominate as secondary, none of which could be eliminated without seriously impairing the results, any more than the smaller wheels or cogs in a watch could be removed without stopping the action of the mainspring or other, as they seem, more essential portions of the mechanism. Geographically, the process of residual concentration through the action of chemical agents is at its 


\section{I. C. RUSSELL-CONCENTRATION AS A GEOLOGICAI PRINCIPLE}

maximum degree of efficiency in warm, humid regions, and diminishes when toward the region of less mean annual temperature or of summer warmth and toward regions of little or no rainfall. A like graduation, but dependent on variation in temperature and humidity, is also present from densely plant-clothed areas to either hot or cold deserts.

Concurrently with the production of residual concentrates as with all other products of concentration, in order that important accumulations may result, is the fact that concentration must progress at a greater rate than the process of removal or redistribution. The fact that under given conditions material of a particular kind is concentrated carries with it the conclusion that at the same or other localities depletion is in progress; concentrates in general represent the net result or algebraic sum of the results of agencies tending to bring like kinds of matter together in a given locality over the results of the same or other agencies tending to dissipate or redistribute material.

Residual concentrates, therefore, in order to be extensive or commercially important, can only occur in regions where they are to a conspicuous degree shielded from, or are beyond the reach of, destroying or diminishing agencies. Of the agencies which remove surface material, streams and glaciers are the most important. As the production of residual concentrates goes on most actively in regions of abundant precipitation, they are especially liable to removal through the denuding operations of streams, but derive protection from the vegetation usually present in such localities. In going from regions of heavy precipitation to regions of little or no rain, rock decay diminishes, but the efficiency of the rain wash and streams in promoting denudation also diminishes, on account of diminution in the amount of water available to do the work, although other factors, as decrease in density of vegetation, also enter into the problem. Although the conditions are highly complex, the result of observation seems to be that in warm, humid regions rock decay, and consequently the concentration of residual material, is most apt to be in excess of depletion, owing to the denuding action of streams. It is in such regions that the prospector looks for the most extensive residual concentrates, although even at present the most arid regions hold out promises of rich rewards.

Of the agencies tending to remove residual concentrates, glaciers work most thoroughly and most efficiently. So generally is this fact known that no well informed prospector would expect to find commercially valuable surface concentrates in regions scoured by glaciers during geologically recent times. 
The habitat, so to speak, of residual mineral and rock fragments, which are left when the more soluble associated material of the original rocks is removed, is the surface portion of land areas to the depth of the zone of weathering. Below the surface of saturation, or the water table, solution and deposition are active processes, but the former is far less prominent than the latter, and leached mineral or rock masses are not prominent. As is familiar to miners the world over, residual and oxidized minerals and ores are limited in depth by the upper surface of the zone of saturation, and below that horizon deposition resulting in concentration and not depletion is the rule. The search for residual concentrates is thus "limited by a definite and easily determinable horizon, unless a recent or comparatively recent rise of the level of ground water has occurred.

\section{SURFACE $\triangle N D$ SUBSURFAOE PREOIPITATES}

The substances taken into solution by percolating water in the zone of weathering present great variety. In fact, all known chemical elements are present in greater or less abundance in surface and subsurface water. The zone of weathering may truthfully be said to be a vast laboratory in which the concentration of mineral matter is brought about not only on account of chemical inertia at the temperatures present, as in the production of residual concentrates, but a great variety of chemical precipitates also result and furnish examples of concentrated material frequently of great commercial importance.

\section{ETAPORATION}

The concentration of mineral matter other than residual material, at the earth's surface and in the zone of weathering, through the dominant agency of chemical processes results principally from evaporation, decrease in temperature, and chemical reactions.

Evaporation leads to the precipitation of mineral matter from water solutions to some extent while the water is in the zone of weathering, but principally from surface water, in part returned to the surface after short subterranean journeys, as from the surface of the land and from streams, lakes, seas, and the ocean. Resulting from this process, which is coextensive with the earth's surface, many and important chemical concentrates are produced. As a rule, the substances laid aside in this manner, in more or less well defined accumulations, are such as are readily soluble, but are present in such abundance that evaporation quickly produces a state of saturation, as, for example, in the case of calcium carbonate, sodium chloride, and sodium sulphate. 
Water in the zone of weathering is either under the dominant control of gravity, as when it occurs in fissures, caverns, etcetera, or occupies the interspaces between the pebbles or grains of gravel or sand and moves in response to the pull of gravity exerted directly or indirectly under the form of hydraulic pressure, or adheres to the solids present and is held by them as surface films, owing to molecular attraction. In general and as it appears universally, the free water content of cellular and porous rocks is not saturated with any of the substances it contains in solution, and evaporation does not lead to precipitation. When, however, the free water percolates away, leaving only films of water adhering to the surfaces of the solids present, evaporation is favored and all the mineral matter contained in the water films is frequently precipitated. This process of subsurface evaporation goes on most actively adjacent to the surface of land areas and decreases essentially in arithmetic ratio with increase in depth. It is most active in open textured rocks, like beds of boulders and pebbles, and decreases inversely with diminution in the cellular condition of the containing terranes. By this process precipitates are formed which incrust the surface of the solids present, and in the case of terranes composed of sand grains, pebbles, etcetera, in many instances increases in volume until the fragments are cemented and under favorable conditions the interspaces are completely filled.

The process of subsurface concentration just outlined is modified in a conspicuous manner by climatic conditions, and especially by the degree of humidity and temperature. Its results are most conspicuous in regions of small rainfall and of high temperature, and especially where periodic or occasional rains occur in regions of high mean annual or seasonable temperature, and are less common in cold, humid regions. Examples of the growth of this process are furnished by the cemented subsurface crusts or alkaline hard-pans of arid regions and by the lime cemented gravels occurring near the surface in humid regions.

A delicate adjustment between the conditions favoring subsurface concentration by evaporation and the removal of the precipitates formed in solution is frequently manifest by the deposits in question. In regions of small rainfall the precipitates which may be termed perennial contain such readily soluble substances as sodium sulphate and carbonate and calcium sulphate, but in more humid regions, where the volume of percolating water is greater, such salts are usually eliminated and the more abundant calcium carbonate alone remains. A still more delicate adjustment of the same nature is frequently illustrated in humid regions, where in many instances incrustations of calcium carbonate occur principally or wholly on the under surfaces of the pebbles and stones in 
gravel deposits, it being in such situation that the solvent action of percolating water is least and where, also, the conditions favoring precipitation from slowly percolating water are more favorable.

The process of subsurface concentration of mineral matter, owing to evaporation, leads to the hardening of rock outcrops, the production of efflorescence, gypsum rosettes, similar incrustations in caverns, and is a factor favoring the growth of stalactites and stalagmites.

The process of concentrating readily soluble minerals, owing to the evaporation of water from the surface of the land, is illustrated by the efflorescence which forms in desert regions, where, owing to the drying of porous material, water is drawn from below the surface by capillary action and the mineral matter it holds in solution is precipitated as the water evaporates. This snow, as it appears when viewed from a distance, of hot arid lands, frequently contains sodium chloride, sulphate and carbonate, as well as boracic acid, calcium, etcetera, and is at times of commercial value.

The rise and outflow of previously subsurface water from springs leads to important changes in the conditions exerting an influence on the solvent power of the emerging waters which favor concentration of mineral matter in a variety of ways. Decrease of pressure, freedom of escape for dissolved gases, decrease in temperature of water which comes from a considerable or great depth, and a rise in temperature from the water of hillside springs (the latter favoring the precipitation of calcium carbonate), exposure to the air thus preventing oxidation, and most of all the emergence of the water into the light, thus favoring in a high degree the growth of living organisms, and particularly of algæ, lead to the formation of abundant concentrates, the most common of which are calcium carbonate, silica, gypsum, iron oxide, inorganic acids, etcetera. In this complex process evaporation is an important factor, particularly in the precipitation of silica by hot springs and geysers.

During the transit of surface water supplied in part by springs and seepage to inclosed lakes and the ocean, concentration by evaporation continues, although precipitates from this cause in streams seem seldom, if ever, to be found.

The waters of streams on reaching inclosed lakes or inland seas evaporate and the mineral matter they contain is concentrated. Frequently, as is well known, this process leads to precipitation and the formation of deposits of calcium carbonate and calcium sulphate. A similar process operates in lagoons shut off from the ocean, and the ocean itself is a vast evaporating jar in which brine is concentrated both locally and under 
exceptional conditions, and the point of concentration and deposition for any of the substances present in solution.

In the process just outlined, concentration by evaporation is the leading control, but chemical reactions, life, and variation in temperature, escape of gases which enhance the solvent power of water, and other conditions exert important influences.

Of the secondary conditions, variation in temperature has received less attention than perhaps any of the other modifying conditions enumerated, but its importace is indicated on a grand scale by the precipitation of sodium sulphate from the waters of Great Salt lake during the prevalence of abnormally cold seasons.

The escape of gases from water when pressure is relieved, as in the case of springs which have their sources deep in the earth, or when greater surface of exposure to the air is brought about, as in water percolating into caverns, is also an important and at times a controlling factor leading to precipitation. The best known illustration of this process is the escape of carbon dioxide, which when present in water gives it enhanced power to hold calcium bicarbonate in solution. The critical study of this process from a geological point of view, and concerning other gases in addition to carbon dioxide, remains to be undertaken, but gives promise of furnishing instructive information.

The results of concentration by evaporation fall into two groups, each of which may be of commercial value. Solids are precipitated from solutions which themselves remain as liquid concentrates or mother liquors, and while yet in the open evaporating pans in which they were produced arein some instances of economic importance as well as of scientific interest. A place is thus provided in our general scheme of classification of natural concentrates for the brines of dead seas and buried saline waters, in some instances rich in bromides, iodine, etcetera, as well as rock-salt, gypsum, anhydrite, and for saline deposits of varied character, such as are mined at Stassfurt. The geographic distribution of the solid and liquid products of concentration resulting from evaporation while still present at the surface of the earth is controlled mainly by the distribution of solar heat and of precipitation. The conditions favoring this production and preservation increase from locality to locality with increase in mean annual temperature and with decrease in precipitation, providing the requisite conditions of relief of surface, such as the pressure of inclosed basins, are present. With a knowledge of the climatic conditions essential to the production of concentrates by evaporation and of the nature of the receptacles required, a means is furnished for determining the conditions under which buried fossil salts and brines of similar char- 
acter were produced. In this manner ancient concentrates serve a purpose analogous to that supplied by plant and animal fossils in determining the nature of former climatic oscillations. In attempting to apply this principle, however, it should be remembered that during early geological eras the earth's interior heat may have played the role now assigned to solar heat, and also that throughout the time embraced in geological history the residual heat of lava beds may have produced similar results.

Of the concentrates resulting mainly from evaporation at the earth's surface as in the zone of weathering, the next class in order of abundance after the brines and salts contains the products resulting from the evaporation of petroleum.

Petroleum, when occurring in quantities of commercial importance, is, as previously stated, a result of mechanical concentration, but when evaporated under natural conditions yields gases, semi-solids, and solids. The gases may be widely diffused in rocks as in the air, or concentrated, according to the presence or absence of collecting or storage reservoirs. The residues, either in a liquid or solid condition, left by the evaporation of the more volatile portions of the original fluid, remain in the cavities and fissures of greater or less size, or more or less completely saturate porous rocks in the superficial portion of the earth's crust, or are produced at the surface. The residues resulting from the evaporation of petroleum constitute the naphthas, mineral tar, asphaltum, ozokerite, grahamite, albertite, etcetera.

In this connection, again, a knowledge of the mode of concentration by which fractional parts of previously more complex or more heterogeneous material are segregated, aided by a knowledge of the nature and kinds of receptacles necessary for the storage and preservation of the concentrates produced, is an aid in the search for commercially valuable deposits of the nature just considered.

\section{SUBLIMATION}

Analogous to the process of evaporation is the process of sublimation, whereby matter is changed from a solid to a vaporous condition without alteration in composition and redeposited as a solid when the temperature is sufficiently lowered. The process of sublimation as commonly recognized, and so far as its geological action is concerned, requires a high temperature in reference to the sun-derived heat of the earth's surface, the source of which is the earth's interior. The heat is transferred to the earth's surface as a part of the functions of volcanoes, and the substances sublimed may be considered as by-products of volcanic activity. 
The most common geological deposits which owe their concentration to the process under consideration (not at present considering water as a part of the category or attempting to strictly define sublimation as a physical-chemical process) are sulphur, arsenic, mercury, etcetera. Owing to the high temperatures present in volcanoes, inclusive of their funnels and solfatara stages, and the variety of substances usually present, the chemical activity is conspicuous, and it is difficult to differentiate the concentrates resulting from sublimation simply from the results produced by chemical reactions, evaporation, etcetera. For the present at least it seems best from a geological point of view to make a special class of the concentrates resulting from the direct action of the earth's internal heat, when transposed to the earth's surface, and term these fumarolic and solfataric products. The concentrates of this class produced essentially in the absence of water, except in the condition of steam, are analogous to hot-spring deposits, in the production of which the earth's internal heat is the dominant agency, in association with water. In fact, the concentrates formed in connection with fumaroles and solfataras may be considered as the products of hot-gas springs. In a manner similar to the way in which the deposits from hot-water springs grade into other forms of aqueous deposition, so the fumarolic deposits merge with other accumulations resulting from the action of volcanic heat at the surface or in the rocks through which the conduits of volcanoes pass.

Another phase of volcanic activity, which, however, can at present be considered but briefly, is the concentration of gases arising from the disassociation of the elements of substance exposed to the high temperatures. prevailing in volcanic vents. By this process various gases result, as, for example, hydrogen, oxygen, nitrogen, ammonia, etcetera, and various acids in a gaseous condition; but in general and perhaps always, so far as the geologist is especially concerned, these concentrates, owing to their great chemical activity, and also, as a nearly universal rule, the absence of suitable reservoirs in which they can accumulate and be permanently stored, do not demand attention as geological deposits.

\section{CHEMICAL REACTION RESULTING IN PRECIPITATION}

A highly varied group of natural chemical concentrates have as the principal or controlling agency leading to their production what is termed chemical reaction, or the mutual disassociation of the elements in two or more compounds when brought into intimate relations with one another under certain conditions of temperature, pressure, etcetera, and the production of one or more new compounds which may separate out and be placed by themselves. For example, if a water solution contain- 
ing ferric carbonate is exposed to the air, the iron at normal surface temperatures and pressures will exchange its carbon dioxide for oxygen and be precipitated as ferric oxide. In other words, there is the process in nature whereby chemical precipitation leads to the concentration of ferric oxide.

The example cited above, of the precipitation of ferric oxide, is a chemical process, normal, as one may say, to the established order of physical conditions of the outer earth. Hence, together with other similar or analogous instances in which the bringing of bodies or volumes of material into intermediate association leads to the precipitation or segregation of one form of matter apart from other forms, it may be termed concentration owing to chemical reactions.

In an extension of our classification indicating methods of concentration the subdivisions of the results of chemical precipitation may be based on the nature of the products or on the processes included in this concentration. Suggestive categories may be formed by each of these methods, but for our present purpose and for the sake of economizing space subdivisions based on the major features of the processes involved are here considered.

Chemical reactions resulting in the concentration and preservation of various forms of mineral matter take place in nature in the main by the (1) union of gases with gases, (2) the union of liquids with liquids; and here we include the union of substances or ions in solution (3) by the union of gases with liquids or solids and by the union of liquids with gases or solids. The significant result of these various unions, so far as the present discussion is concerned, is that solids of specific composition are produced which may be reckoned as geological concentrates.

1. The interaction of gases with gases in nature causes the precipitation of such substances as ammonium chloride, borates of the alkaline earths, sodium carbonate, ferric chloride, and a variety of other products, some of which are of commercial importance. These substances when deposited in and about volcanic conduits, as already stated, are commonly associated with the products of sublimation, and the two classes have been tentatively classed as fumarolic concentrates.

2. The reactions between substances in solution, or, as is perhaps a more accurate statement, the affinity between different ions when substances are in solution, is the fundamental factor in chemical concentration. Principally, however, at or near the earth's surface, chemical unions which lead to the precipitation of solids from solutions are controlled in a conspicuous manner by temperature changes, evaporation, relief of pressure, escape of gases from solutions, vital processes, etcetera, 
certain results of which have already been cited and others will receive attention later. After recognizing the results of these various processes, there remain certain precipitates that result from the commingling of waters with different chemical constitutions, which may be termed concentrates due to chemical reactions.

The surface waters of the earth are dilute chemical solutions, and by their mingling, as when two streams join, springs are tributary to lakes, etcetera, no recognizable precipitates are formed. In inland lakes and the ocean, direct chemical precipitation not dominated by concentration, by evaporation, by vital action, or other processes recognized in our schedule are of such minor importance that no characteristic examples seem recognizable. In the laboratory of the outer film of the lithosphere, or the zone of weathering through which weak chemical solutions are passing, but linger for shorter periods than is the case at the surface above or the zone of cementation below, precipitation on account of chemical reactions is in general of minor importance. Such substances as certain salts of iron, copper, zinc, etcetera, and silica and a few silicates, etcetera, which are formed are closely associated with the residues left from solutions and in general may be classed with them. In the portion of the lithosphere below the zone of weathering, as will be noted later, chemical reactions under the influence of energetic physical conditions become of paramount importance.

3. The union of liquids, or, more precisely, of water with solids, finds its chief field of activity in the zone of weathering, and is illustrated by the hydration of certain minerals, as, for example, the change of anhydrite to gypsum and the alteration that certain of the feldspars experience. Relief of pressure accompanied by the pressure of water, which rocks experience when they pass into the zone of weathering, owing to the removal of previous incumbent terranes, seems to be the leading factor in this change. Although hydration is of importance in the study of the disintegration of rocks and is an agency in preparing material for mechanical concentration, as a direct process leading to the transfer of material from one place to another which is in more or. less complete isolation-that is, as true concentration-it does not seem to play an important role.

\section{Physical-chemical Concentration}

The zone of weathering has been likened to a chemical laboratory in which great results are produced. The operations carried on in it, however, are such as require for the most part low and nearly uniform temperatures and correspondingly small and nearly constant pressures. The 
exceptions are in association with the outward migration of heated waters or of magmas from deep within the earth. It is in the inner earth from which the igneous rocks now at the surface have migrated that the earth's great physical-chemical laboratory is located and those geological processes requiring high temperatures and great pressure are carried on. In the lithosphere below the zone of weathering two important divisions in reference to the processes of concentration may be recognized-an outer zone, in which water may exist in cavities and also because the temperature is not sufficiently high to reach the critical temperature above which the elements of water are disassociated, and an inner zone, or the earth's centrosphere, in which these conditions are reversed.

The zone beneath the zone of weathering is a zone of saturation, whose waters linger or in general migrate but slowly, and where also temperatures are high and pressure enormous and progressively increasing with depth. Under these conditions the chemical reactions are favored and the results, so far as concentration of mineral matter is concerned, are free from the complications that arise when evaporation, sublimation, and influences of life are active. This zone is thus especially favorable for the production of mineral concentrates through the process of chemical reaction, as has already been emphasized by Van Hise, who has named it the zone of cementation. In the zone of cementation cool descending waters meet and commingle with heated ascending waters, and lateral migration of solutions involving changes of temperatures and pressure also occur. The fact that in this zone, which is in a condition of saturation, the water present is under pressure and subject to the laws of hydrodynamics, and in consequence will move from regions of greater to regions of less pressure, irrespective of direction, is sometimes lost sight of. Possibly also in the case of highly heated and saturated rocks the principal governing the diffusion of solutions through membranes or endosmosis may play a part in the migration of matter.

Under the general conditions named-that is, high temperature, saturation, slow movement of water, and hence abundant time for chemical processes to act and great pressure-the one thing that controls concentration is the presence of suitable receptacles in which the materials precipitated may be accumulated and preserved. Such receptacles, as is attested by mineral veins, are furnished by cavities in the rocks. When the cavities are small and in general evenly distributed, we term the process of concentration of mineral matter cementation. When the cavities are larger and cave-like in character, geodes and agates result. When the cavities are produced by fracture and open fissures result, 


\section{I. C. RUSSELL-CONCENTRATION AS A GEOLOGICAL PRINCIPLE}

their filling results in the formation of fissure veins. In case solution furnishes the requisite receptacle, which in general, as it seems, becomes. filled as rapidly as formed, concentration by replacement results.

The great group of concentrates just referred to results from chemical precipitation under the direct and immediate control of physical conditions, chief among which are variations in temperature and pressure. So complex are the conditions leading to the filling of cavities in the zone of cementation and so little are they understood that it does not seem practicable to classify the results in terms of the agencies in operation. In order to make convenient subdivisions among the results produced, resort must seemingly be had to the character of the receptacles in which concentrates have been placed, as has been done in classifying mineral veins, geodes, agates, amygdules, etcetera, or else the mineral composition of the concentrates themselves employed for a like purpose and various ores and mineral deposits recognized. As is well known, each of these methods has been employed, but without formulation of a definite system of classification.

In the zone of cementation, as has been mentioned, the temperature is normally below the critical temperature for water. A higher temperature, especially if the fusion of rock results, leads in general to the diffusion and not to the concentration of mineral matter. Under certain conditions, however, when heterogeneous material is in a fused condition, or when part of a magma erystallizes, leaving other portions still liquid, gravitation may lead to the separation of lighter from heavier magmas, or to the settling of solid products from a cooling magma, or from one in which decrease of pressure has favored partial crystallization. These two processes, although distinct, depend on selective gravitation and may progress at the same time. The nature of the magmas composing the earth's highly heated interior is known in part from the study of the extrusions of plastic or liquid rock discharged by volcanoes, but in general it is only the cooled and crystallized material which was present in the earth's centrosphere and has been forced outward that is available for examination.

The study of igneous rocks has shown that concentration during the process of cooling has resulted in the formation of minerals, but in general these are not gathered into groups or masses, but disseminated through the rock. The layers of the disseminated concentrates are crystals of various minerals, and the ones of commercial value are principally feldspar and certain gems. In certain instances, however, as in the case of pegmatite veins, original concentration from a magma seems to have occurred; but even in these instances later concentration 
through the agency of highly heated percolating water seems to have followed. In fact, it seems inadrisable at present to attempt to draw a dividing line between the results of crystallization and segregation of minerals directly from magmas and subsequent concentration, owing to the action of percolating heated water while the mass was slowly cooling. These two processes must grade one into the other and their results merge in a complete manner.

Magnetic segregation, during which the heavier minerals crystallizing out of a magma migrate toward the bottom of the mass and lighter minerals toward its summit, or outer portion, appears to be a fundamental principle which should lead to the production of definite concentration. Examples of this method appear to be furnished at the Sudbury district, Canada, as described by Colman.

\section{Vital Concentration}

THE $\triangle$ GENCIES INVOLVED

In attempting to briefly review the various ways in which living organisms lead to the concentration of mineral matter, two divisions should be made - one to include what may be termed the geological work of plants, and the other to embrace the similar functions performed by animals. Under each of these divisions the composition of the substances segregated suggest subordinate headings. For the sake of economizing space, however, only certain typical examples will be cited.

The principal substances of geological importance segregated by plants and animals as a part of their vital functions are carbon, silica, and calcium carbonate; but a more extended analysis would include potash, soda, magnesia, sulphur, iodine, etcetera.

\section{CARBON}

In the whole range of selective functions, either inorganic or organic, under review, perhaps no better illustration is furnished of the principle made prominent in this address than by the manner in which land plants decompose the carbon dioxide of the air and fix the carbon in their tissues. This process of obtaining carbon from an invisible gaseous source and giving it a solid form is the mainspring of a great series of geological as well as of industrial results. The processes by which peat beds and other accumulations of carbon are produced are too well known to be discussed in detail at this time. An important auxiliary principle of wide application, of necessity operating in conjunction with the principle of concentration, however, is perhaps best illustrated by III-BULL. GEOL. Soc. AM., VoL, 18, 1906 
the deposit of carbon in question-that is, the fact that accumulations of material must be present or their conservation insured for, in general, a great length of time in order to be of geological or economic importance. Methods of preservation thus become only secondary in importance to the methods of primary concentration. In the case of carbon, accumulations are made; this concentration is promoted in several ways, prominent among which is submergence in water, which, as a part of the process, is rendered to a conspicuous degree antiseptic by reason of certain products of organic origin, as is well known in the case of the ambercolored water of swamps; still longer preservation is involved when peat-bog, drift timber, etcetera, become buried beneath sediment or other deposits, which serve to compress it as well as exclude the ravenous oxygen. Another important method of preservation, and one to which but little heed has been given, is illustrated in the vast tundras of another latitude, where vegetable matter comparable in volume with that of our largest coal fields has it decay arrested by low temperature. The incipient coal beds of the tundra marshes owe their preservation literally to a process of cold storage. In the review that is evidently demanded of the glacial records of approximately Permian age in various parts of the world, the suggestion that some of the late Paleozoic coal beds are of tundra origin may, perhaps, make certain facts significant which would otherwise be passed by with scant attention.

\section{CALOIUM OARBONATE}

The methods of concentration through the action of plants, of calcium in combination with carbon dioxide, recently so clearly demonstrated by Weed in reference to hot-spring deposits, and by Davis concerning the so-called marl of freshwater lakes, are of fundamental importance to geologists. If such striking results are now produced by this method of concentration, our cherished faith in uniformatism should certainly lead us to scan the history of past times with the hope of learning when this function began to be exercised and what part it has played in recording geological events. The question is pertinent. Do the more or less local and frequent lenticular beds of limestone in certain formations now partly crystalline schists, represent the products of concentration brought about by algæ?

Other and more familiar methods by which the concentration of calcium carbonate is brought about need only be mentioned to indicate the important place they hold in the scheme of classification of the widely extended operations of nature under review, which in truth have made the earth habitable by living creatures. The hard parts of foraminifera, 
corals, crinoids, mollusks, etcetera, as is well known, form terranes which in the aggregate measure thousands of cubic miles. The geological and industrial importance of these organic accumulations and the clearness with which they demonstrate the continuous action of life in segregating mineral matter throughout the zoic division of geological time speak eloquently in favor of the definite recognition of the principle of concentration as a geological process.

\section{SILIOA}

What has been said relative to the concentration of calcium carbonate might be said again concerning silica, with but little change in the wording. The diatoms among plants and radiolaria and sponges, especially among animals, have throughout eons of time been forming stones for the geological temple, and through the solution and reconcentration of the material secreted have furnished a cement for other stones in the structure.

The importance of the principle of concentration concerning the resultant or by-products of the vital functions of plants and animals might be illustrated at greater length, and the conditions leading to the accumulation of deposits of iron, phosphorus, sulphur, and many other substances, dwelt upon, but enough has perhaps been said to show the importance of the subject.

\section{STMMARY}

Attention has been invited to the broader phases of the processes active in nature which lead to the concentration of mineral matter. A classification of the processes referred to has been suggested, the primary divisions of which take cognizance of the dominant form of energy, whether mechanical, chemical, physical-chemical, or vital, which in certain large groups of the changes considered exert the major control. Subdivisions of these primary classes, based on determining or qualifying conditions and on selective or transposing agencies, have also been introduced, as it is thought they will be of service to the geologist. The scheme is intended to be sufficiently elastic to admit of the interpolation of as yet unrecognized determining or qualifying conditions or agencies and of a minute classification of products or results.

As an attempt has been made to show, the field of operation of the principles presented is as extensive as the earth, and embraces not only its surface, but its interior, and is as far reaching as geological time. Although an underlying principle has been dwelt upon and emphasized, 
it is not to be understood that it stands alone or is the sole guide which a geologist should follow in reaching for materials of industrial importance. Concentration in one way or another has filled nature's storehouses, but the origin of the receptacles, their size, association, the conditions favoring their preservation, etcetera, are important matters to be considered. The very activities which lead to storage necessitate as a part of their functions depletion in many instances of previous accumulations. As in so many other geological processes, destructional and constructional action are involved in the various processes of concentration, and the result is in many instances the algebraic sum of the two. In dwelling on the process which favors accumulation, the concurrent activities favoring dissipation need to be borne in mind and at some other season given a place of prominence.

\section{In Conolusion}

From the sands at our feet I have selected a pebble and held it to the light. It is perhaps not a flawless crystal, but can with greater truth be termed bort, which may be put to industrial uses instead of treasured on account of its beauty or rarity. The pebble, as I have identified it, is a true and broadly underlying principle, which is worthy of recognition, which should be given a place by geologists, and especially in books dealing with the application of our science to commercial industries. By understanding the methods by which storehouses of the earth have been filled; the seeker for hidden treasures will be better able to locate his claims. 